https://www.journal-imab-bg.org

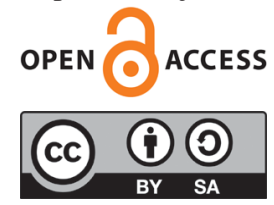

Case report

\title{
COMPLICATION AFTER MANDIBULAR FRACTURE- CASE REPORT
}

\author{
Petko Petrov ${ }^{1}$, Hristo Daskalov ${ }^{2}$ \\ 1) Department of Facial and Mandibular Surgery, Faculty of Dental Medicine, \\ Medical University - Plovdiv, \\ 2) Department of Oral Surgery, Faculty of Dental Medicine, Medical University \\ - Plovdiv, Bulgaria.
}

\section{SUMMARY}

Introduction: The teeth in the fracture line, as a risk factor for various complications in the mandibular fractures treatment process, continue to be widely discussed issue in scientific circles. The aim is to present a rare case of complication occurred 20 years after a mandibular fracture.

Material: The case presents a patient with undiagnosed 33rd tooth apex fracture, passing next to the tooth, during a mandibular fracture treatment. The X-ray is presented by a fragment of the apex of the tooth migrated medially and causing a lesion on the medial side of the root.

Results: Surgical removal of the root fragment, curettage of the bone defect with subsequent bone substitution, and collagen membrane coating for guided bone regeneration procedures were performed. The recovery period showed no complications.

Conclusion: Undiagnosed tooth apex fractures, located in the mandibular fractures fracture line, pose a complications risk factor.

Keywords: mandibular fractures, complications, tooth in the fracture line,

\section{INTRODUCTION}

Mandibular fractures are common as part of facial and mandibular traumatology. Their treatment is a responsible task, aiming both at restoring the mandible integrity and preventing any subsequent complications. [1] The causes of complications occurring during and after conducted mandibular fractures treatment are the subject of research by many authors because sometimes they occur years after the initial treatment. [2, 3] In order to optimize the healing process, different treatment methods are proposed, with the basic idea of a sufficiently stable fracture line immobilization and fixation. [4, 5] The occurrence of complications in the healing process is often associated with an etiological cause of an inflammatory nature, and abscesses, phlegmons, osteomyelitis or other severe conditions may occur. [6] In order to prevent these complications, Ii is important to observe the basic principles of fracture treatment and to use sufficient amount and type of imaging tests to maximize the accurate visualization of the mandibular bone trauma area. An important stage of the imaging is the establishment of a tooth in the fracture line and its state. The presence of such a tooth can hinder the initial bone healing, on the one hand, and on the other, it may lead to later complications that are not associated with the main healing process. [7, 8] Such complications may be late inflammatory reactions, periapical lesions, cysts, etc.

The aim of this study is to present a rare case of complication occurred 20 years after a mandibular fracture.

\section{PRESENTATION OF THE CASE}

The 41 years old patient, S. H., was referred to an Oral Surgery specialist due to a regularly occurring fistula around the 33rd tooth. Medical history: The patient reports that for one year a fistula appears between the 32nd tooth and the 33rd tooth, from which effuses a white matter. There is no pain or other complaints related to the fistula or teeth adjacent to it. The patient reported no trauma in the area during the last few years. He was treated surgically by a colleague, but with no effect. In reread to any past illnesses, the patient reported a mandibular fracture occurred 20 years ago, but with no complications in its treatment.

Status. During the examination no deviation in the extraoral status was established. The intraoral status showed a mucosa with normal color and turgor. The jaw is intact. An altered color of the 33rd tooth was established. The same was treated endodontically 20 years ago, just after the mandibular fracture healing. In front of the tooth in the middle of the root was established a small fistula opening of the mucosa, through which a probe entered the lateral surface of the middle region of the 33rd tooth root.

Paraclinical tests: An X-ray imaging was administered: segmental X-ray in the area of a 22nd tooth and 23rd tooth. Presence of a fractured apex of the 33rd tooth, migrated medially to the 22 nd tooth and presence of a bone lesion covering $2 / 3$ of the medial surface of the root were established. 
Fig. 1. X-ray of the 33rd tooth

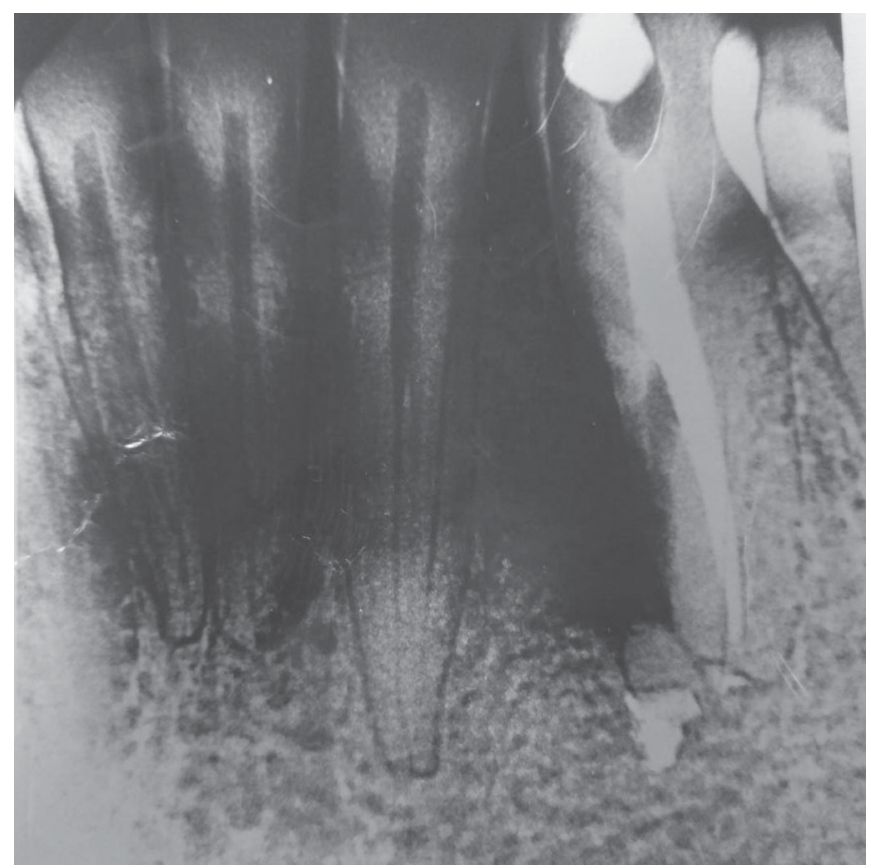

Treatment: After a discussion was decided to perform surgical removal of the root fragment, curettage of the bone defect with subsequent bone substitution, and collagen membrane coating for guided bone regeneration procedures. The procedures were followed by a smooth post-operative period with no complications.

Fig. 2. Established bone lesion

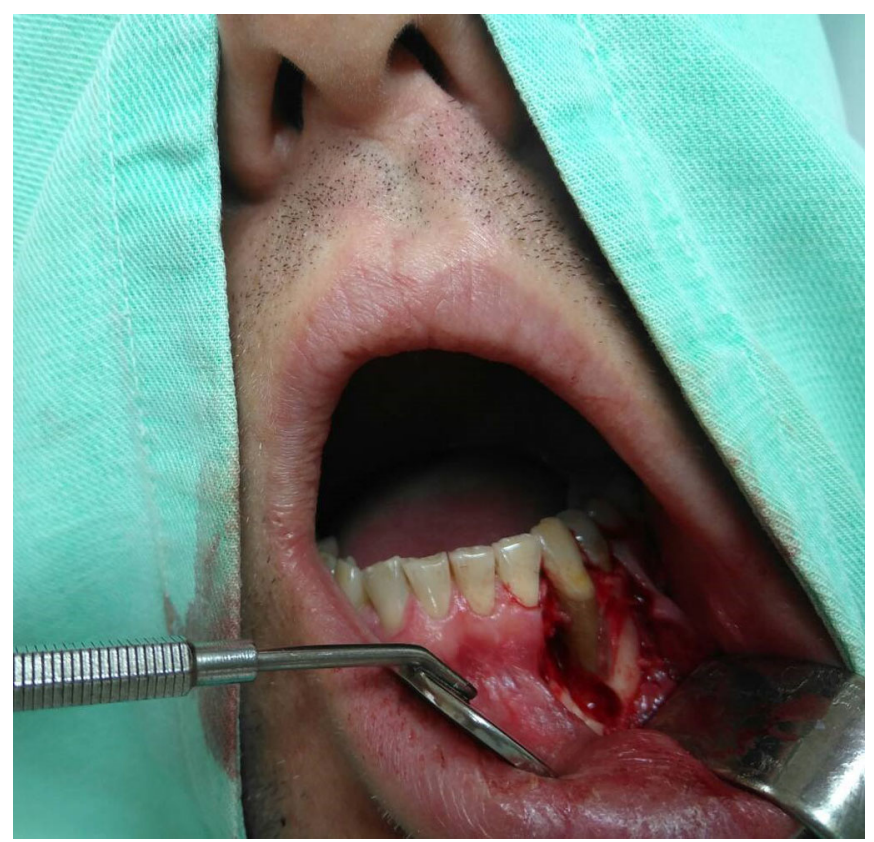

Fig. 3. Completed surgical intervention

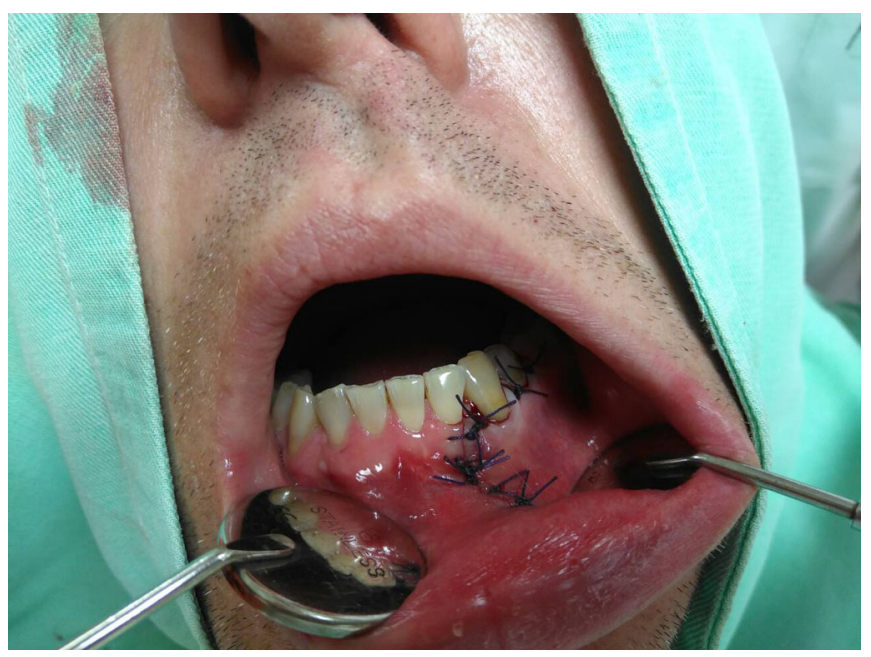

\section{DISCUSSION}

The identification of risk factors for the development of complications in mandibular trauma is a major concern for surgeons in the modern healthcare system. (9) The mandibular angular fractures with the presence of a penetrated third molar show the highest degree of complication, while the retention of a retained third molar does not increase the risk of complications. (10) Numerous complications have been observed in the clinical practice during the treatment of mandibular fractures associated with the presence of teeth in the fracture line and described in the medical literature. $(11,12,13)$

The case of a complication occurring 20 years later presented in our study is quite rare. An exact endodontic treatment of a 33rd tooth, which was adjacent to the fracture line, was performed. The capabilities of X-ray imaging 20 years ago were much more limited. This is probably the reason for the misdiagnosis.

\section{CONCLUSIONS:}

The undiagnosed tooth apex fractures, located in the mandibular fractures fracture line, pose a risk factor both for early and late complications. 


\section{REFERENCES:}

1. Alpert B. Managment of the complications of mandibular fracture treatment. Oper Tech Plast Reconstr Surg. 1998 Nov;5(4):325-333. [Crossref]

2. He SL, Xiao SS. [Analysis of relative factors associated with postoperative infection of mandibular fractures.] [in Chinese] Shanghai Kou Qiang Yi Xue. 2017 Aug;26(4):429433. [Pubmed]

3. Marie Furr Àİ, J Schweinfurth, W May. Factors Associated with Long-Term Complications after Repair of Mandibular Fractures. Laryngoscope; 2006, 116:427-430.

4. Ostrander BT, Wang HD, Cusano A, Manson PN, Nam AJ, Dorafshar AH. Contemporary Management of Mandibular Fracture Nonunion-A Retrospective Review and Treatment Algorithm. J Oral Maxillofac Surg; 2018, Feb 6. pii: S02782391(18)30093-4.

5. Zavlin D, Jubbal KT, Echo A,
Izaddoost SA, Friedman JD, Olorunnipa O. Multi-institutional Analysis of Surgical Management and Outcomes of Mandibular Fracture Repair in Adults. Craniomaxillofac Trauma Reconstr; 2018, Mar;11(1): 41-48.

6. Tveterås K, Haahr PA, Skjødt S. Mandibular fractures. 2. Treatment, complications and late sequelae. Ugeskr Laeger; 1990, Sep 17; 152(38):2716-9.

7. Vyas A, Mazumdar U, Khan F, Mehra M, Parihar L Purohit C. Late results of treatment of mandibular fractures. Czas Stomatol; 1990, Feb; 43(2):85-90.

8. Zweig BE. Complications of mandibular fractures. Atlas Oral Maxillofac Surg Clin North Am; 2009 Mar;17(1):93-101.

9. Christensen BJ, Mercante DE, Neary JP, King BJ. Risk Factors for Severe Complications of Operative Mandibular Fractures. J Oral Maxi- llofac Surg. 2017 Apr;75(4): 787.e1787.e8. [PubMed] [Crossref]

10. Ulbrich N, Ettl T, Waiss W, Gosau M, Moralis A, Reichert TE, Mueller S. The influence of third molars in the line of mandibular angle fractures on wound and bone healing. Clin Oral Investig. $2016 \mathrm{Jul} ; 20(6)$ : 1297-302. [PubMed] [Crossref]

11. Kavlakov $\mathrm{P}$, Lalabonova $\mathrm{Hr}$, Bebechev Iv. [Behavior of teeth within the mandibular fractures line.] Stom /S/. 1991; 2:33-36. [in Bulgarian]

12. Lalabonova Hr, Bebechev Iv. Impact of teeth in the fracture line on the course of mandibular fractures treatment process. Annual Proceeding (Scientific Papers) - IMAB. 2001; 7(2):190-192.

13. Balaji P, Balaji SM. Fate of third molar in line of mandibular angle fracture - Retrospective study. Indian J Dent Res. 2015 May-Jun; 26(3):262-6. [PubMed] [Crossref]

Please cite this article as: Petrov P, Daskalov H. Complication after mandibular fracture- case report. J of IMAB. 2019 Jul-Sep;25(3):2603-2605. DOI: https://doi.org/10.5272/jimab.2019253.2603

Received: 18/02/2019; Published online: 16/07/2019

Address for correspondence:

Hristo Daskalov, DMD, PhD

Department of Oral Surgery, Faculty of Dental Medicine,

3, Hristo Botev Blvb, 4000 Plovdiv, Bulgaria

tel: 00359888589242

E-mail: hdaskalov@hotmail.com 